\title{
The Organizational Neuroscience of Emotions
}

\author{
Sebastiano Massaro, Ph.D.
}

University of Surrey, Surrey Business School, Guildford GU2 7XH, United Kingdom; The Organizational Neuroscience Laboratory, 27 Old Gloucester Street, London WC1N 3AX, United Kingdom. E-mail: s.massaro@surrey.ac.uk

Massaro S. (2019). The Organizational Neuroscience of Emotions. In: The Cambridge Handbook of Workplace Affect; Eds.: Yang L., Cropanzano R.S., Daus C., \& Tur V.A.M.; Chapter 3, Cambridge University Press.

February, 2019

Please do not circulate/cite/copy without the author's consent. 


\begin{abstract}
This work contributes to research in workplace affect by presenting an Organizational Neuroscience perspective on emotions. Methodological motivations are explored and a theoretical parallel drawn between Affective Event Theory (Weiss \& Cropanzano, 1996) and neural circuitries of information processing. Neuroscience research relevant to the organizational affective literature is then explained by covering the broad domains of intraindividual and inter-personal affect. Topics addressed include basic emotions, emotional contagion, and emotional intelligence, among others. Suggestions for future research emerge at the end.

Keywords: Affective Event Theory; Affect and Cognition; Emotions; Methodology; Organizational Neuroscience.
\end{abstract}




\section{The Organizational Neuroscience of Emotions}

The study of emotions has taken center stage in several areas of organizational scholarship over the past few decades. Since in the mid-1990s with the seminal Affective Events Theory (AET; Weiss \& Cropanzano, 1996), which proposes that discrete workplace "affective events" elicit "affective responses" that then influence attitudinal and behavioral outcomes, research has experienced an affective revolution (Barsade, Brief, \& Spataro, 2003). Work on emotional contagion (e.g., Barsade, 2002), discrete emotions (e.g., Lazarus \& Cohen-Charash, 2001), and multilevel integrations (e.g., Ashkanasy, 2003a; Elfenbein, 2007), among other topics, has rapidly advanced both theory and practice, becoming integral to the lexicon of organizational scholars (Brief \& Weiss, 2002).

More recently, Becker and Cropanzano (2010), building on information deriving from increasingly sophisticated methods of investigating human neurophysiology and cognition, proposed Organizational Neuroscience $(\mathrm{ON}) . \mathrm{ON}$ is an informative perspective incorporating knowledge about the neural substrates supporting individuals' cognitive machinery into organizational theory (Becker, Cropanzano, \& Sanfey, 2011). Although still nascent, interest in using neuroscience as an opportunity to advance explanations of administrative behavior has rapidly spread to other domains of managerial research, including strategic management (Powell, 2011) and entrepreneurship (Day, Boardman, \& Krueger, 2017; Drover, Massaro, Cerf, \& Busenitz, 2017). Moreover, journals have dedicated special issues to neuroscience (e.g., Organizational Research Methods, Journal of Business Ethics, Organizational Behavior and Human Decision Processes), and at several scholarly meetings (e.g., Academy of Management, Society for Industrial and Organizational Psychology, American Psychological Association) the number of sessions devoted to the topic has steadily increased. Yet as typical of an emerging 
field, the development of ON has been characterized by both hype and hope (see Ashkanasy, Becker, \& Waldman, 2014). In addition, scholars have pursued a variety of theoretical perspectives (e.g., Lee, Senior \& Butler, 2012), resulting in a fragmented research program thus far. This chapter, while arguing for a more unified development of ON, purposely aims at infusing workplace affect research with neuroscience knowledge to show why and in what ways ON can offer a productive platform to advance organizational studies on emotions.

First, some caveats. Investigating the intersection of emotion and neuroscience is certainly not new. From Hippocrates (460-370 BC), who in De morbo sacro (400BC; Hippocrates \& Mann, 2000) argued that the brain gives rise to emotions and judgments, to Descartes (1596-1650) contending that human "passions" cannot be localized in the body (Descartes, 1649); from William James's (1842-1910) peripheralist theory, which holds that emotions are stimuli-driven automatic perceptions of specific bodily changes (James, 1884), to the debate on the relations between emotions and cognition (Lazarus, 1982; Zajonc, 1984), people have long been fascinated by the association between emotions and the brain. Here I focus on the most recent research in affective neuroscience as inaugurated by neuroimaging techniques. These powerful methods have greatly advanced our understanding of how the brain encodes, accumulates, and retrieves knowledge about emotions; how emotional states regulate and shape cognitive processes, such as decision making; and how emotions influence behavior (e.g., Damasio, 1996; Davidson, \& Irwin, 1999; Lane \& Nadel, 1999; LeDoux, 1998; Panksepp, 1998; Rolls, 2000).

Second, ON is not (and should not be) merely a narrow investigation of activated or deactivated brain areas. Neuroscience, and by extension affective and organizational neuroscience, investigates the entire nervous system and its relationship to behavior (Massaro \& 
Pecchia, 2019). The nervous system is a complex structure comprising central and peripheral autonomic parts, the latter discernible in the sympathetic and parasympathetic systems (i.e., the systems responsible for the "fight-or-flight" and the "rest-and-digest" responses, respectively). Moreover, neuroscience is concerned with multilevel interconnections from the sub-molecular to the cellular, anatomical, behavioral, and social levels of analysis (Cacioppo, Berntson, Sheridan, \& McClintock, 2000; Ochsner \& Lieberman, 2001). Within the ON perspective, for example, an angry employee could be characterized by the combination of low serotonin, high dopamine, and high noradrenaline in the body (Lövheim, 2012), or an altered responsiveness of the brain circuitry amygdala-hypothalamus-periaqueductal gray (Blair, 2012), or increased heart rate mapped onto behavioral processes occurring in certain social interactions (Denson, Grisham, \& Moulds, 2011), or all these features together. As a consequence, many methods, and functional neuroimaging in particular, can be used to capture these points.

Finally, readers should be aware that the terminology of affective science has been used inconsistently in both the organizational (Barsade \& Gibson, 2007; see for an exhaustive thesaurus) and neuroscience literatures: Emotions are complex phenomena involving different interpretations, theories, and focuses of inquiry. Importantly, such a multifaceted body of knowledge offers a valuable point of entry to explore ON initiatives in workplace affect research. As Panksepp (1998) notes, only with concurrent neuroscience analyses can affective concepts be used non-circularly in the scientific discourse.

Thus, I begin by explaining why and in what ways the ON perspective and its core methods matter for emotion research in the workplace. I also draw theoretical parallels to AET, arguably one of the most acknowledged frameworks supporting the scholarship in workplace affect. I then review recent neuroscience evidence on topics relevant to organizational research 
in emotion, considering both the intra-individual and inter-personal dimensions. I conclude by presenting some questions for future research that $\mathrm{ON}$ might address in furthering our understanding of the "emotional workplace."

\section{The Methodological Rationale}

The methodological advancements recently put forward by neuroimaging represent the most logical entry point to substantiate the use of neuroscience in management research (Massaro, 2015). In particular, in affective research, scholars have suggested the existence of a "misalignment of theory and methods" due to the use of self-reported and observational data (Briner \& Kiefer, 2005; Gooty, Gavin, \& Ashkanasy, 2009). Thus, methods capturing the neural and physiological correlates of affect can provide novel and reliable measures that promise to mitigate this unbalance (Becker \& Menges, 2013; Massaro, 2014).

Several peripheral physiological reactions, those automatic responses of the nervous system that generally occur beyond one's awareness, may now be monitored to investigate emotional arousal and valence. These responses include respiration rates and heart rate variability (HRV; Massaro \& Pecchia, 2019), electromyography (EMG) tracing of facial cues (Hazlett, \& Hazlett, 1999), and changes in skin conductance response (SCR; Christopoulos, Uy, \& Yap, 2019). Organizational researchers can also assess neural changes through functional imaging, which more precisely shows "what," "where," and "when" affective events occur in the brain. In particular, electrophysiological methods based on assessing brain electrical activities (e.g., electroencephalography, EEG) or their tomographic quantification (qEEG; Teplan, 2002), or magnetic activity (magnetoelectroencephalography, MEG; Ahlfors \& Mody, 2019) capture cortical events underlying affective states in almost real time (milliseconds). Moreover, functional magnetic resonance imaging (fMRI), which typically assesses the increase in the 
oxygenated blood flow accompanying cerebral activity (Aine, 1995), allows mapping activation of deeper areas in the brain, including the so-named "limbic system" (MacLean, 1952), a cluster of regions strongly involved in our emotional life (Figure 3.1).

[Figure 3.1]

Finally, metabolic imaging, including positron emission tomography (PET), is less common, also due to the use of dangerous ionizing radiations. Despite low spatial and temporal resolutions (30s-minutes), this technique yields high specificity (Cabeza \& Nyberg, 2000).

Given the variety of methods available, Massaro (2017) has recently illustrated a methodological framework to guide ON research (Table 3.1). Accordingly, when investigating affective states as functions of the measurement of neural activity, researchers can best understand and apply these methods by considering their correlational, causational, or manipulating properties.

[Table 3.1]

Importantly, all approaches generate objective measures, improving the examination of emotional experiences in the workplace beyond what could be achieved with observations or subjective data. Moreover, neuroscience tools can often provide real-time information about someone's emotional state, overcoming demand effects that often sway self-reported data (Thorson, West, \& Mendes, 2017). Added to this, due to their unobtrusiveness, many neuroscience instruments allow researchers to assess affective processes without disrupting their dynamics, including those that occur during interpersonal interactions or in real-world organizations.

Finally, thanks to the growing availability of wearable and portable technologies (e.g., smart-watches, portable EEG caps), parallel measurements of different individuals might 
advance our knowledge of such interpersonal affective dynamics as those occurring in emphatic processes within organizations. This feature is also particularly promising in upholding the requirement of ecological validity necessary for ON investigations to thrive (Massaro, 2017).

\section{The Theoretical Rationale}

Methodological advantages have been the driving force behind the ON approach thus far. Yet inquiries into workplace affect offer another valuable prospect to appreciate the informative power of ON. Herein lies the opportunity to integrate and advance management theory with insights from neuroscience theory concerning the functioning mechanisms of the brain.

Specifically, affective research recognizes that emotions are complex states and highly mutable phenomena (e.g., Beal, Weiss, Barros, \& MacDermid, 2005); a better knowledge of their mechanisms and dynamics might thus substantially improve existing theory (e.g., Askanasy \& Humprey, 2011; Brief \& Wiess, 2002) and how affective mechanisms develop within and between organizational actors (Ashkanasy, 2003a; 2003b).

Consider the possible parallel between AET and neuroscience theory on the informationprocessing of emotions (Figure 3.2; see also Elfenbein, 2007 for a comparison between AET and emotions as stimuli driven processes, yet lacking the neuroscience perspective).

[Figure 3.2]

AET is an acknowledged organizational research framework that examines the structure, causes, and consequences of affective experiences at work (Weiss \& Cropanzano, 1996). It starts from the concept that work events are proximal causes of affective reactions: what happens at work can be seen as discrete and cumulative events that trigger employees' internal influences - named "affective reactions" - that then with affective disposition shape organizational behavioral outputs (Weiss \& Cropanzano, 1996; Weiss \& Beal, 2005). 
ON can be of particular help in disentangling what occurs in the black box of individual "affective reactions." Indeed, contemporary neuroscience research contends that affective responses are mental representations that prepare the organism for certain behaviors, usually associated to survival value (Lane \& Nadel, 1999). This concept follows the evidence, generalizable beyond research on emotions, that the brain works as information processing system for external stimuli through a series of complex anatomic and physiological interconnections. These circuits are genetically pre-determined to respond to external stimuli, and connections are reciprocal; they rely both on feedback and feedforward patterns (Tau \& Peterson, 2010).

At its simplest, the starting point, much like the focus on affective events in AET, is that an emotionally salient stimulus in the environment triggers an input process for the brain. We can think about a discrete event, say an unjust happening in the workplace (Barsky \& Kaplan, 2007), a recollection of that occasion, or even a cognition of something emotionally weighted taking place in the organization. Affective mental processes, including perceptions and judgments, can also be subconsciously activated (Chartrand \& Bargh, 2002; Higgins, 1996) as responses to biologically significant triggers (e.g., threats, primary needs, associational cues) through our sensorial or cognitive pathways (e.g., attention, memory, perception). This insight is already significant for $\mathrm{ON}$ research because it provides a neurobiological support for the analysis of both conscious (i.e., the subjective feeling of the evaluation and appraisal of an affective event) and implicit or unconscious (i.e., the detection of a potential stimulus) emotions (Barsade, Ramarajan, \& Westen, 2009). Moreover, it supports the idea that emotional climates in organizations (e.g., stressful administrations, toxic workplaces) can implicitly influence 
employees' affective reactions and ultimately their organizational behaviors by acting at the subconscious level (Carr, Schmidt, Ford, \& DeShon, 2003; Chartrand \& Bargh, 2002).

In the brain, information is carried through the sensory cortex and then routed into the thalamus for processing and, simultaneously, to other specialized cortical structures for further processing (e.g., occipital, temporal lobes). The thalamus is an integrative structure of the brain that plays a major role in regulating arousal, circadian rhythm, and through the thalamo-corticothalamic circuit, human consciousness (Jones, 2012).

There information is also routed to other subcortical areas. Pioneering work by Papez (1937) and MacLean (1952) suggest that emotions are located in a group of subcortical structures called the "limbic system" (MacLean, 1952)1. In particular, within these limbic areas, information reaching the amygdalae promotes the release of hormonal responses through the pituitary system, leads to autonomic activations through the brain stem, and, through the basal forebrain, supports mechanisms of arousal (LeDoux, 2000; see also for a fuller account of emotion circuits in the brain). These relays are essential because they promote adaptive bodily (i.e., hormonal, autonomic, and neuro-modulatory) and behavioral reactions preparing the organism to respond to the stimulus (Phelps, 2009).

Processed information is thus sent to the hippocampus, entering into the memory system to be organized, disseminated, and associated with the cortical areas related to long term retention. Together with one's unique background, this information shapes affective traits and

\footnotetext{
${ }^{1}$ Current affective neuroscience has allowed research to move from a global view on emotions to recognize distinctive aspects of each emotion, each forming a part of its own circuit and different part of the traditional limbic circuit (Ward, 2010).
} 
attitudes (Ekman \& Davidson, 1994). This state of neuroscience knowledge may help refine organizational theory on affect by suggesting a neurobiological mechanism of interaction between the processing of new information from the environment and existing internal information stored in the memory. Moreover, this knowledge can support further investigations on the interplay between one's affective reactions, dispositions, and attitudes in the workplace (e.g., Thoresen, Kaplan, Barsky, Warren, \& de Chermont, 2003).

Finally, following evaluation of the significance of the affective stimulus, modulation of the automatic behavior, cognitive appraisal, and associated decision processes the brain produces a final response: actual decision, normally involving the prefrontal cortex, as well as parallel and associated motor responses involving the motor cortex (Adolphs \& Damasio, 2001). Once again, this passage proves relevant to workplace research because it suggests that emotions and higherlevel cognition are highly interrelated processes requiring overlapping neural systems. Thus changes in cognitive abilities necessarily relate to changes in emotion, and vice versa. Organizational research should then investigate them in conjunction.

Neuroscience research has proposed several integrative theories of emotions (e.g., LeDoux, 2000), including the "somatic marker hypothesis" (Damasio, 1996), a theory evolutionarily grounded and generalizable across emotional events. This theory holds that when a person is confronted with emotional stimuli, both the brain and the body change. Somatic markers are thus internal bodily states connected to external events that influence cognitive processing. This insight is important to guide $\mathrm{ON}$ research because it supports predictions that variations in the intensity of bodily reactions to a stimulus are markers of the intensity of emotions. Put in other terms, by appreciating neural and physiological responses, organizational researchers can open a window to observe and assess the affective reactions of professionals. 


\section{Between Affective Neuroscience and Workplace Affect Research}

Having explained the processing mechanism of affective events in the brain, I now review neuroscience knowledge relevant to workplace affect research. In line with the most recent accounts of emotions in ON (Haley, Hodgkinson, \& Massaro, 2018), I organize this evidence in the areas of intra- and inter-individual emotions. Specifically, I present evidence related to basic emotions, complex intra-individual affective processes, and inter-individual social emotions. As often occurs in neuroscience and $\mathrm{ON}$, this is not a fixed categorization, rather a pragmatic device to organize current knowledge.

\section{Basic Emotions}

A widely accepted understanding of emotions is that they are affective states focused on a specific target or cause, short lived and intense, and entail a range of synchronized features and neurophysiological responses (Ekman, 1992; Phelps, 2009). The so-called basic emotions (also known as primary) represent the most common categorization in both neuroscience (e.g., Ortony \& Turner, 1990) and organizational scholarship (e.g., Elfenbein, 2007). Despite debates about the actual number of basic emotions (e.g., Plutchik, 1980), Ekman's original research (Ekman, Friesen, \& Ellsworth, 1971) acknowledges six cross-cultural emotions (see also Ekman, 1994), that can be encoded through facial expressions. These emotions are anger, fear, disgust, sadness, happiness, and surprise. As we shall now see, each presents characteristic neural circuitry and correlates (Lindquist, Wager, Kober, Bliss-Moreau, \& Barrett, 2012; see also for a metaanalysis). Understanding their neural correlates and mechanisms is particularly important for workplace research because it would answer calls for higher specificity in empirical research on emotions when investigating affective states that are generalizable across organizations and their actors (e.g., Barsade et al., 2003). 
Anger. Organizational research has increasingly explored anger as a key emotion to explain workplace phenomena (e.g., Geddes \& Callister, 2007). Intriguingly, research has reported both negative outcomes from anger expression, such as reduced productivity and job satisfaction, increased job stress, and mutual comebacks (Friedman, Anderson, Brett, et al., 2004; Glomb, 2002), as well as positive ones. For instance, anger drives problem solving, promotes mutual understanding, fuels work motivation, and improves attitudes as well as may offer competitive advantage by fostering an adaptive drive for competition and learning (Gibson \& Callister, 2010; Fitness, 2000; Kiefer, 2002). Given this imbalance and the ongoing discussion about the theorizing of anger in the workplace (Geddes \& Callister, 2007), researchers have supported the use of neuroscience methods as "essential to begin to capture more objectively how anger is experienced and expressed" (Gibson \& Callister, 2010, p. 19; see also for a review).

Identifying the neural foundations of anger has, however, proven difficult: metaanalytical evidence shows that the medial and ventromedial and lateral prefrontal cortex (PFC), the anterior and posterior cingulate cortex, and the thalamus all play critical roles in the neural circuitry (Murphy, Nimmo-Smith, \& Lawrence, 2003; Phan, Wager, Taylor, \& Liberzon, 2002). More recently, Denson, Pedersen, Ronquillo, and Nandy (2009) have investigated the neural correlates of anger in an experiment in which they elicited anger by addressing participants in an insulting manner; this induction was then followed by a fMRI session. The researchers found that self-reported feelings of anger, but of no other emotion, positively correlated with activation in the left dorsal anterior cingulate cortex. Moreover, general aggression was associated with increased activity in the left dorsal anterior cingulate cortex, but displaced aggression was not; instead, displaced aggression was significantly associated with increased activity in the medial 
prefrontal cortex. Extending these results, Blair (2012) investigated reactive aggression to suggest that the prefrontal cortex moderates such circuits in the presence of anger.

Moving beyond brain imaging, electromyography (EMG) has been used to measure facial markers of anger. Dynamic expressions induce EMG activity interpretable as facial mimicry more evidently than in cases of static expressions (Sato, Fujimura, \& Suzuki, 2008). Moreover, HRV has been proposed as key correlate of adaptive emotion regulation in response to anger (Denson, Grisham, \& Moulds, 2011). A recent ON study uses the Prisoners' Dilemma framework to show that elicited anger in research participants reduces their cooperation, individual monetary gains, as well as their global aggregated performance relative to control conditions (Castagnetti, Massaro, \& Proto, 2018). This evidence can be explained through a mechanism of anger-induced emotional regulation, which is accurately traceable through depression of HRV high frequency bands.

Disgust. Disgust is a response of refusal towards something or someone potentially harmful, nasty, or unpleasant. It has been theorized as a withdrawal emotion (Rozin \& Fallon, 1987), and is also often presented as one of our "hardwired" emotions; disgust would have evolved as a response to unpleasant foods that could be a potential source of harm (Wicker, Keysers, Plailly, et al., 2003). Perhaps because disgust is habitually associated with taste and other such primary senses, it has rarely been investigated in organizational research.

One notable exception is Pelzer (2002), who argues that disgust is the most severe reaction to negative perceptions occurring in organizational life. Specifically, such an effect is morally salient as constituting "a revolt of the body against a perception of something unacceptable, harmful, damaging, poisoning" (p. 841). Further supporting this concept, research 
shows that people tend to react to certain moral violations with a sense of disgust (e.g., Skarlicki, Hoegg, Aquino, \& Nadisic, 2013).

By providing a direct example of the usefulness of ON, Cropanzano, Massaro, and Becker (2017) present disgust as an emotion involved in deontic justice, a key driver of workplace fairness (Cropanzano, Goldman, \& Folger, 2003), suggesting that the insula - a small region of the cortex hidden behind the temporal lobes - is a core site for the existence of "justice rules." This evidence resonates with mainstream neuroscience research: Mataix-Cols, An, Lawrence, et al. (2008) show that the anterior part of the insula is activated in response to facial expressions of disgust. Moreover, Moll, de Oliveira-Souza, Moll et al. (2005) reveal that the experience of disgust, when dissociated into "pure disgust" vs "moral indignation," recruits both the frontal and temporal lobes. This evidence supports the role of the prefrontal cortex in moral judgment and may be helpful to integrate the most recent scholarship on justice arguing that disgust sensitivity is a strong predictor of extreme deontic judgment (Robinson, Xu, \& Plax, 2018).

The key involvement of the insula in disgust has been confirmed by several other methodological perspectives. For instance, Calder, Keane, Manes, Antoun, and Young (2000) show that lesions on the anterior insula indicate deficits in the experience of disgust, and electrical stimulation of the anterior insula during neurosurgery triggered nausea-a strong marker of disgust (Jones, Ward, \& Critchley, 2010). Moreover, the insula is thought to be a core site for interoception, one's perception of the body's internal state, which is a construct strongly associated with the cognitive processing of emotional awareness (Barrett \& Simmons, 2015).

While the insula is center stage in the disgust's neural circuit, it is also worth mentioning that Phan et al. (2002) conducted a meta-analysis of PET and fMRI activation studies, showing 
that disgust can be associated with the subcallosal basal ganglia, a region of the brain generally involved in motor functional coordination. Sprengelmeyer, Rausch, Eysel, and Przuntek (1998) argue that the activations seen in the basal ganglia in response to disgust may represent a state of preparedness triggered by a warning stimulus to process emotionally salient information. Thus in organizational settings, the basal ganglia may play a key role for workers in arranging appropriate "affective responses" towards emotional events (Panksepp, 1998). Future research in ON might find valuable to consider these regions, likely in conjunction with the insula, as candidate areas to explain violations of organizational behaviors such as fairness, trust, and justice (Massaro \& Becker, 2015).

Fear. Fear is likely the most investigated emotion in neuroscience. Its core neural circuit develops around the amygdala (LeDoux, 2003). Phan et al. (2002) show that nearly 60\% of fear induction studies report activation in the amygdala. The amygdala has been implicated in the recognition of fearful facial expressions (Adolphs, Tranel, Damasio, \& Damasio, 1995), fear conditioning (Bechara, Tranel, Damasio, et al., 1995; LaBar, LeDoux, Spencer, \& Phelps, 1995), and in evocation of fearful emotional responses from direct stimulation (Halgren, Walter, Cherlow, \& Crandall, 1978). The amygdala also appears to be crucial in the detection and coordination of appropriate responses to threat and danger (Amaral, 2002).

Yet one major cross-disciplinary challenge in affective research is the ability to reliably distinguish fear and anger (Stemmler, Heldmann, Pauls, \& Scherer, 2001). To tackle this issue, Whalen, Shin, McInerney, et al. (2001) compared neural activation of fearful, angry, and neutral faces, to find that the ventral amygdala shows higher activity when facing a condition with a negative valence (i.e., fearful or angry) in comparison to the control condition; yet, when the 
fearful and angry face conditions were equated, the dorsal amygdala was activated only in the former.

Moving to the analyses of the wider nervous system, studies on fear have also identified an extensive pattern of sympathetic activations (Kreibig, 2010). Fear-associated responses show unique cardiac sympatho-vagal activation and withdrawal dynamics (Rainville, Bechara, Naqvi, \& Damasio, 2006), indicating that these features can be used as autonomic biomarkers for this basic emotion. The increasing specificity of these findings suggests that in organizational research anger, which is often challenging to dissociate from other negative emotions following induction procedures (i.e., video or picture stimuli, or memory recollections; see also Phelps, 2009), can be discerned by a concomitant assessment of subjects' neurophysiological correlates. This opportunity is of particular relevance for $\mathrm{ON}$, given the increasing availability of portable tools assessing peripheral measures readily applicable to organizational investigations.

Sadness. Sadness is another relevant emotion for the workplace. It is associated with absenteeism (Porath \& Pearson, 2012), but also with increased organizational citizenship behavior and workplace deviance (Lee \& Allen, 2002). In leadership, Lewis (2000) reveals that followers facing a "sad leader" felt less enthusiasm and more fatigue compared to those observing a leader expressing anger or no emotion.

In neuroscience, sadness induction studies generally report activation in the cingulate cortex (e.g., Barrett, Pike, \& Paus, 2004). Specifically, Liotti, Mayberg, Brannan, et al. (2000) show that sadness induces activity in the anterior cingulate cortex. In recent years, this brain region has become an important topic of research because it involves specific processing modules for both cognitive and emotional information and integrates input representations from cognitive and emotional networks (Bush, Luu, \& Posner, 2000). Anatomical and brain-mapping 
studies support the distinction between a cognitive-affective division of the cingulate. The presence of a dorsal-cognitive and rostral-ventral affective division may thus promote research seeking to further understand the interactions between cognition and emotion associated to sadness (Lane, Reiman, Axelrod, et al., 1998). Research shows that the dorsal division signals the occurrence of conflicts in information processing, thereby triggering compensatory adjustments in cognitive control; this signalling regulates cognitive control to prevent further conflicting appraisals (see Bush et al., 2000).

Finally, of particular impact for that organizational behaviour research interested in the role of rewards to motivate employees' motivation (e.g., Wiersma, 1992), Gehring and Willoughby (2002) find that the cingulate engages when research participants were told the outcomes of their decisions in a gambling task, indicating that this region is susceptible to aversive results related to external reward. This function could thus work following a costbenefit evaluation that integrates information about outcomes of past actions and present environmental requests (Rushworth \& Behrens, 2008).

Happiness. The neuroscience of positive emotions has only recently received scientific attention (Burgdorf \& Panksepp, 2006). Biological theories suggest that there may be several distinct forms of positive emotions, but all are closely related to sub-neocortical brain regions: happiness seems to engage a widely distributed neural network (Ward, 2015). In one of the early functional imaging studies of happiness, George, Ketter, Parekh, et al. (1995) investigated the brain activity of healthy women during transient sadness and happiness using PET. The participants were required to recall life events that they found happy, sad, and neutral; they were also presented happy, sad, or neutral human faces. Happiness was associated with significant and widespread reductions in cortical cerebrovascular flow, especially in the right prefrontal and 
bilateral temporal-parietal regions. Adding to this body of knowledge, Sato, Kochiyama, Uono, et al. (2015) investigated the structural neural substrate of happiness and found a positive relationship between a score of subjective happiness and gray matter volume in the right precuneus, suggesting that this area mediates subjective happiness by integrating its emotional and cognitive components.

Over the years, neuroimaging research has consistently shown that the ventral striatum and putamen respond to presentation of happy faces (e.g., Whalen, Rauch, Etcoff, et al., 1998), pleasant pictures (e.g., Davidson \& Irwin, 1999), competitive and sexual arousal (Rauch, Shin, Dougherty, et al., 1999). These areas are characterized by rich innervations of dopaminergic neurons, which respond to incentive reward and motivation towards reaching planned goals (Telzer, 2016). This convergence represents a useful insight for that growing body of organizational research interested in exploring the causal links between happiness, employees' rewards, and organizational behavior outputs (e.g., Lyubomirsky, King, \& Diener, 2005; Ryan \& Deci, 2001).

Surprise. There is growing evidence suggesting that dopaminergic systems in the brain are recruited in anticipatory positive affective states. Moreover, research has shown that the amygdala's central nucleus, the cholinergic neurons of the nucleus basalis, and their innervation of the posterior parietal cortex, are critical to surprise enhancements in associative learning (Wessel, Danielmeier, Morton, \& Ullsperger, 2012). Wessel et al. have investigated the neural sites of surprise by administering an error-monitoring/novelty-oddball task in which the frequency of new surprising trials was matched to the frequency of errors. Combining electroencephalographic recordings and event-related functional magnetic resonance imaging 
(fMRI), they compared neural responses to errors with neural responses to novel events, revealing increased activity in the posterior medial frontal cortex and anterior midcingulate.

This evidence suggests strong associations between awareness of surprising events and associative learning, as processes mediated by shared neural systems. Thus these findings could further knowledge in organizational research on the way in which surprising situations, such as a newcomer's entry experience (Louis, 1980) or a person-environment fit (Caplan, 1987), influence employees' learning. In the future, on the practical side, this knowledge could also allow for the formulating of surprise-eliciting "nudges" as possible interventions to improve organizational learning.

\section{Intra-individual Emotional Processes}

While studies on basic emotions have been one of the most visible backers of affective neuroscience, research has also focused on better our understanding of the complexity surrounding individuals' emotional experiences (Panksepp, 1998). While it is not possible to provide a full account of this emerging research stream, I mention here three areas worth of attention for research in the workplace.

Emotional intensity and valence. The individual propensity to respond, more or less intensively, to affect-related events is an important area of workplace affect research. For example, den Bos, Maas, Waldring, and Semin (2003) show that people high in affect intensity display robust affective responses after experiencing outcome and procedural fairness. However, when affect intensity is low there are marginal fairness effects. This evidence suggests that affect intensity may play a fundamental role in the psychology of affective reactions to unfair events, offering generalization to several contextual and organizational circumstances (den Bos 
et al., 2003). Thus, advancing knwoledge on why and in what ways people differently weigh their emotions is a compelling and timely call.

Neuroscience has provided important insights into how strongly people feel their emotions (e.g., Cooper \& Knutson, 2008). For one example, Ewbank, Barnard, Croucher, Ramponi, and Calder (2009) suggest that the amygdala's response to emotional stimuli is not a function of valence alone, but also a function of the stimuli's significance. In a fMRI experiment, these authors find that the left amygdala has a significantly larger response to high impact stimuli than to neutral and low impact ones. This finding is significant because it shows the discriminatory potential of neuroimaging in assessing salience of affective states, and might thus be useful to enrich that body of organizational research looking at unraveling this aspect (e.g., Rafaeli \& Sutton, 1989).

For another example, adding to this knowledge, Cunningham, Van Bavel, and Johnsen (2008) provide fMRI evidence that the relation between affective valence and the amygdala's activity can be modulated by evaluative goals. When research participants were asked to provide affective evaluations on facial stimuli, the amygdala's modulation was more pronounced for positive than for negative information. Altogether, this evidence supports the view that our brain systems processes both intensity and valence of emotional information in a flexibly manner.

Complex emotions. Affective neuroimaging research has produced a growing number of studies on self-conscious emotions, those emotions that are evoked when a person reflects on their self- or evaluates their self in relation to the environment (Lewis, 1993). These processes can occur implicitly or explicitly and require the capacity for introspection and self-knowledge leading to complex emotions such as regret, guilt, shame, embarrassment, and pride (MüllerPinzler, Krach, Krämer, \& Paulus, 2016). Importantly for ON, these emotions can drive 
immediate punishment or reinforcement of behavioral outcomes, and therefore can motivate social behavior, which in turn helps to retain social structures (Tangney, Stuewig, \& Mashek, 2007). Within this domain, research on regret has offered a landmark example to investigate the involvement of the orbitofrontal cortex and of the amygdala during choice, when the brain is anticipating possible future consequences (i.e., anticipated regret; Coricelli, Dolan, \& Sirigu, 2007).

Emotional regulation. A growing stream of research in affective neuroscience concerns the mechanisms of emotional regulation, which are widely acknowledged constructs related to emotional labor (Grandey, 2000). Neuroscience research has recently shown that emotional regulation includes a series of complex processes such as reappraisal, selective attention and emotional extinction, each featuring distinct neural correlates (see for review Dunsmoor, Niv, Daw, \& Phelps, 2015; Ochsner \& Gross, 2005).

Braunstein, Gross, and Oschner (2017) cluster these mechanisms into four categories: explicit-controlled; implicit-controlled; explicit-automatic; and, implicit-automatic regulation strategies. These clusters are based on a neuroscience-driven analysis of the orthogonal dimensions explicit—implicit, which accounts for the goals a person regulate, and controlledautomatic, which instead covers the nature of the emotional process at stake. Thus, a placebo mechanism is an explicitly-automatic processes that recruits both the ventromedial and dorsolateral prefrontal cortex (Wager \& Atlas, 2015); whereas, emotional extinction is an implicit-automatic process recruiting the ventromedial prefrontal cortex alone (Phelps, Delgado, Nearing, \& LeDoux, 2004). Comparatively, reappraisal, selective attention, and distraction belong to the explicit-controlled cluster and involve prefrontal cortex, inferior parietal gyrus, and dorsal anterior cingulate cortex (Ochsner, Bunge, Gross, \& Gabrieli, 2002; Van Dillen, 
Heslenfeld, \& Koole, 2009). Finally, implicit-controlled regulation strategies, such as affective labelling, automatic goal pursuit, and reversal learning, involve ventromedial and postero-medial prefrontal cortex and the dorsal anterior cingulate cortex (Buhle, Silvers, Wager et al., 2014; Lieberman, 2007).

This framework suggests the possibility to recognize emotional regulation mechanisms on the basis of different activations in the neural systems involved. Moreover, it provides the opportunity to form hypotheses and predictions on the influence of situational and workplace factors on emotional regulation strategies. For instance, stress can impair explicit-controlled regulation by impairing optimal prefrontal functioning (Arnsten, 2009). Thus, as Braunstein et al. (2017) argue, it is also possible to deduce that implicit-automatic emotional regulation strategies would not be as impacted by stress because stress reinforces non-prefrontal dependent responses.

\section{Interpersonal and Social Emotions}

Affective neuroscience research is often accompanied by investigations in the social domain. Already Charles Darwin (1896) suggested that emotional expressions evolved both as a means of social communication and to determine others' intentions. Indeed recognizing the emotional states of others is a critical component of social interactions, because we use our emotional responses to regulate our behavior towards others. An interpersonal ON perspective on emotions is thus useful when moving from investigations of individual actors to those on dyads, teams, or groups, where workers can experience emotions related to and interconnected with those around them.

Emotional contagion, affective empathy, and Theory of Mind. The way in which individuals represent the emotional states of others has been a major area of interest for both 
organizational (e.g., Barsade, 2002; Kellett, Humphrey, \& Sleeth, 2002; Hareli, \& Rafaeli, 2008) and neuroscience scholars (e.g., Ruby \& Decety, 2004). Neuroscience research has proposed that three main systems, supported by partially separable neural circuits, are involved in our capacity to understand other people's emotions (Singer, 2009).

Emotional contagion. The first system concerns our ability to understand others' motor intentions and action goals. This system is often associated to mirror neurons (see Gallese \& Goldman, 1998). Mirror neurons represent a cluster of premotor cortex neurons in the monkeys that "fire" when they either perform goal-related movements or watch others, including humans, doing the same (Rizzolatti \& Craighero, 2004). Correspondingly, research has shown evidence for the possible existence of mirror neurons in humans. Despite an intense debate on the topic (Keysers, 2009), research has shown that in humans the inferior frontal cortex and the anterior cingulate respond when a person sees another one experiencing an emotion, leading to the idea that those areas could be the neural sites for emotional contagion (Keysers \& Gazzola, 2006).

Affective empathy. According to Kanske, Böckler, Trautwein, and Singer (2015), there are two further neural systems that can help individuals to understand the emotions of others. One route, known as the affective route or simulation theory, involves the direct ability to imitate and thus understand others' emotions and results in empathy. This route generally involves the anterior insula and middle anterior cingulate cortex. Neuroscience research suggests that empathy represents the first step of a succession that begins with affect sharing, a subsequent imitation of another person's feelings, which may then motivate other-related concerns, including engagement in helping behavior (Singer, 2009). Moreover, this process enables to detached affective empathy from the closely linked process of emotional contagion, the phenomenon of having one person's emotions and related behavior directly trigger 
similar patterns in other people (Barsade, 2002). Differently from empathy, in the latter a person would not realize that the other's emotions were the trigger: Emotional contagion would not be an empathic response as such.

Neuroscience research has also converged around the idea that there is an underlying mechanism of shared brain networks which give humans the ability to empathize (Decety, 2010). Intriguingly, when investigating the neural substrates of empathy neuroscientists tend to use paradigms in which both the participant and a confederate received painful stimulations: Singer, Seymour, O’Doherty, et al. (2004) found an overlap between the receiving and observing conditions in various brain areas, including the bilateral anterior insulae and middle anterior cingulate cortex.

Theory of Mind. The third mechanism requires people representing and reasoning about others' beliefs and thoughts, a process referred to as mentalizing or Theory of Mind (TOM). This path involves the ventral temporoparietal junction, along with anterior and posterior midline regions (Dodell-Feder, Koster-Hale, Bedny, \& Saxe, 2011). A meta-analysis by Bzdok, Schilbach, Vogeley, et al. (2012), which investigated the neural networks activated during ToM, supports these findings. Moreover, Schurz, Radua, Aichhorn, Richlan, and Perner (2014) find that the temporoparietal junction and medial prefrontal cortex are consistently activated in ToM. Importantly, however, while these networks form the basis of ToM, differentiated patterns within the overall network are engaged during different tasks. For example, there are specific activation clusters for false-belief tasks, wherein the temporo-parietal junction is activated (Aichhorn, Perner, Weiss, et al., 2009), and for rational action judgment tasks, wherein the paracingulate cortex is activated (Walter, Adenzato, Ciaramidaro, et al., 2004). 
This remark is particularly germane for $\mathrm{ON}$, given that one frequent criticism of the $\mathrm{ON}$ perspective is that neuroscience experimental paradigms often rely on situations fixed a priori and not based in the real world. Indirectly tackling this concern, Wolf, Dziobek, and Heekeren (2010) investigated ToM in close to real-life conditions by using a paradigm that involves the video-based "Movie for the Assessment of Social Cognition" (Dziobek, Fleck, Kalbe, et al., 2006). In this study, the authors show that brain areas such as the superior temporal sulcus, temporoparietal junction, medial prefrontal cortex, temporal poles, and precuneus are activated depending on the task's components. Thus, face processing and recognition activate the occipito-parietotemporal cortices; language comprehension the temporal lobes, lateral prefrontal cortex, and precuneus; and, self-awareness the dorsomedial prefrontal cortex and the precuneus.

Emotional intelligence and Leadership. Emotional intelligence (EI) represents a consistent focal point for research in the workplace (e.g., Law, Wong, \& Song 2004). Although the neural substrates of EI are still largely unknown, it is recognized that the prefrontal cortex may play a crucial role. For instance, Kruger, Barbey, McCabe, et al. (2009) studied a unique sample of combat veterans in order to examine strategic and experiential EI. They find that these capabilities depend on distinct neural correlates. Ventromedial PFC damage diminishes strategic EI and thus obstructs the understanding of emotional information; dorsolateral PFC damage diminishes experiential EI, impairing the perception and integration of emotional information. These findings are relevant for ON research because they suggest that EI should be investigated under its individual components and in conjunction with cognitive intelligence.

Finally, the most developed area in ON, which has also shown implications for emotional research, concerns leadership (e.g., Antonakis, Ashkanasy, \& Dasborough, 2009). Largely concentrated in the work by Waldman and colleagues, and in the use of qEEG (Waldman, 
Balthazard, \& Peterson, 2011), a rich body of research in neuroleadership has bloomed over the last few years. Of relevance for this work's purpose, these researchers have suggested that qEEG coherence measurements can be optimal means to examine those leadership behaviors, which are likely to require the interface between the brain's emotional and cognitive systems (Cacioppo, Berntson, \& Nusbaum, 2008). Specifically, they report that the presence of high coherence in the right hemisphere of leaders could imply greater emotional balance and ToM (Thatcher, North, \& Biver, 2007).

\section{Closing Thoughts and Future Research}

In this work I undertook an ON approach to investigate the thriving and multifaceted domain of workplace affect, arguing that neuroscience can provide a substantial step towards furthering research on emotions in organizational studies. Notwithstanding the multitude of organizational and neuroscience research on affect, which necessarily constrained this work, and the important headway that neuroscience has made in the past two decades, many questions at the interface between these two fields remain unanswered. For instance, how can organizational research on cognition further integrate the evidence coming from affective neuroscience? What kinds of employees are most vulnerable to grasping others' emotions, and can they be "mapped" neuro-physiologically? Are dual-system accounts of behavior in management adequate to fully capture the complexity of affectivity in the workplace? Can neurofeedback help workers learn to be more in tune with others' emotions, towards creating improved organizational climates? These are just some of the intriguing questions that will likely populate future ON research on emotions. 


\section{References}

Adolphs, R., \& Damasio, A. R. (2001). The interaction of affect and cognition: A neurobiological perspective. In J. P. Forgas (Ed.), Handbook of affect and social cognition (pp. 27-49). Mahwah, NJ: Lawrence Erlbaum Associates Publishers.

Adolphs, R., Tranel, D., Damasio, H., \& Damasio, A. R. (1995). Fear and the human amygdala. Journal of Neuroscience, 15, 5879-5891.

Ahlfors, S. P., \& Mody, M. (2019). Overview of MEG. Organizational Research Methods, 22, $95-115$.

Aichhorn, M., Perner, J., Weiss, B., Kronbichler, M., Staffen, W., \& Ladurner, G. (2009).

Temporo-parietal junction activity in theory-of-mind tasks: falseness, beliefs, or attention. Journal of Cognitive Neuroscience, 21, 1179-1192.

Aine, C. J. (1995). A conceptual overview and critique of functional neuroimaging techniques in humans: I. MRI/FMRI and PET. Critical Reviews in Neurobiology, 9, 229-309.

Amaral, D. G. (2002). The primate amygdala and the neurobiology of social behavior: implications for understanding social anxiety. Biological Psychiatry, 51, 11-17.

Antonakis, J., Ashkanasy, N. M., \& Dasborough, M. T. (2009). Does leadership need emotional intelligence?. The Leadership Quarterly, 20, 247-261.

Arnsten, A. F. (2009). Stress signalling pathways that impair prefrontal cortex structure and function. Nature Reviews Neuroscience, 10, 410-422.

Ashkanasy, N. M. (2003a). Emotions in organizations: A multilevel perspective. In F. Dansereau \& F. J. Yammarino (Eds.), Research in Multi-level Issues, (pp. 9-54). Oxford, UK: Elsevier/JAI Press.

Ashkanasy, N. M. (2003b). Emotions at multiple levels: An integration. In F. Dansereau \& F. J. 
Yammarino (Eds.), Research in Multi-level Issues, (pp. 71-81). Oxford, UK: Elsevier/JAI Press.

Ashkanasy, N. M., \& Humphrey, R. H. (2011). Current emotion research in organizational behavior. Emotion Review, 3, 214-224.

Ashkanasy, N. M., Becker, W. J., \& Waldman, D. A. (2014). Neuroscience and organizational behavior: Avoiding both neuro-euphoria and neuro-phobia. Journal of Organizational Behavior, 35, 909-919.

Barrett, J., Pike, G. B., \& Paus, T. (2004). The role of the anterior cingulate cortex in pitch variation during sad affect. European Journal of Neuroscience, 19, 458-464.

Barrett, L. F., \& Simmons, W. K. (2015). Interoceptive predictions in the brain. Nature Reviews Neuroscience, 16, 419-429.

Barsade, S. G. (2002). The ripple effect: Emotional contagion and its influence on group behavior. Administrative Science Quarterly, 47, 644-675.

Barsade, S. G., \& Gibson, D. E. (2007). Why does affect matter in organizations?. Academy of Management Perspectives, 21, 36-59.

Barsade, S. G., Brief, A. P., \& Spataro, S. E. (2003). The affective revolution in organizational behavior: The emergence of a paradigm. In J. Greenberg (Ed.), Organizational behavior: The state of the science (pp. 3-52). Hillsdale, NJ: Erlbaum

Barsade, S. G., Ramarajan, L., \& Westen, D. (2009). Implicit affect in organizations. Research in Organizational Behavior, 29, 135-162.

Barsky, A., \& Kaplan, S. A. (2007). If you feel bad, it's unfair: A quantitative synthesis of affect and organizational justice perceptions. Journal of Applied Psychology, 92, 286-295. 
Beal, D., Weiss, H., Barros, E., \& MacDermid, S. (2005). An episodic process model of affective influences on performance. Journal of Applied Psychology, 90, 1054-1068.

Bechara, A., Tranel, D., Damasio, H., Adolphs, R., Rockland, C., \& Damasio, A. R. (1995).

Double dissociation of conditioning and declarative knowledge relative to the amygdala and hippocampus in humans. Science, 269, 1115-1118.

Becker W.J. \& Menges J.I. (2013). Biological implicit measures in HRM and OB: A question of how not if. Human Resource Management Review, 23, 219-228.

Becker, W. J., \& Cropanzano, R. (2010). Organizational neuroscience: The promise and prospects of an emerging discipline. Journal of Organizational Behavior, 31, 1055-1059.

Becker, W. J., Cropanzano, R., \& Sanfey, A. G. (2011). Organizational neuroscience: Taking organizational theory inside the neural black box. Journal of Management, 37, 933-961.

Blair, R. J. R. (2012). Considering anger from a cognitive neuroscience perspective. Wiley Interdisciplinary Reviews: Cognitive Science, 3, 65-74.

Braunstein, L. M., Gross, J. J., \& Ochsner, K. N. (2017). Explicit and implicit emotion regulation: a multi-level framework. Social Cognitive and Affective Neuroscience, 12, $1545-1557$.

Brief, A. P., \& Weiss, H. M. (2002). Organizational behavior: Affect in the workplace. Annual Review of Psychology, 53, 279-307.

Briner, R. B., \& Kiefer, T. (2005). Psychological research into the experience of emotion at work: definitely older, but are we any wiser? In N. M. Ashkanasy, C. E. J. Hartel, \& W. J. Zerbe (Eds.), The Effects of Affect in Organizational Settings (pp. 281-307). Howard House, Wagon Lane, Bingley, UK: Emerald Buhle, J. T., Silvers, J. A., Wager, T. D., Lopez, R., Onyemekwu, C., Kober, H., ... \& Ochsner, 
K. N. (2014). Cognitive reappraisal of emotion: a meta-analysis of human neuroimaging studies. Cerebral Cortex, 24, 2981-2990.

Burgdorf, J., \& Panksepp, J. (2006). The neurobiology of positive emotions. Neuroscience \& Biobehavioral Reviews, 30, 173-187.

Bush, G., Luu, P., \& Posner, M. I. (2000). Cognitive and emotional influences in anterior cingulate cortex. Trends in Cognitive Sciences, 4, 215-222.

Bzdok, D., Schilbach, L., Vogeley, K., Schneider, K., Laird, A. R., Langner, R., \& Eickhoff, S. B. (2012). Parsing the neural correlates of moral cognition: ALE meta-analysis on morality, theory of mind, and empathy. Brain Structure and Function, 217, 783-796.

Cabeza, R., \& Nyberg, L. (2000). Imaging cognition II: An empirical review of 275 PET and fMRI studies. Journal of Cognitive Neuroscience, 12, 1-47.

Cacioppo, J. T., Berntson, G. G., \& Nusbaum, H. C. (2008). Neuroimaging as a new tool in the toolbox of psychological science. Current Directions in Psychological Science, 17, 62-67.

Cacioppo, J. T., Berntson, G. G., Sheridan, J. F., \& McClintock, M. K. (2000). Multilevel integrative analyses of human behavior: social neuroscience and the complementing nature of social and biological approaches. Psychological bulletin, 126, 829-843.

Calder, A. J., Keane, J., Manes, F., Antoun, N., \& Young, A. W. (2000). Impaired recognition and experience of disgust following brain injury. Nature Neuroscience, 3, 1077-1078.

Caplan, R. D. (1987). Person-environment fit theory and organizations: Commensurate dimensions, time perspectives, and mechanisms. Journal of Vocational Behavior, 31, 248267. 
Carr, J. Z., Schmidt, A. M., Ford, J. K., \& DeShon, R. P. (2003). Climate perceptions matter: a meta-analytic path analysis relating molar climate, cognitive and affective states, and individual level work outcomes. Journal of Applied Psychology, 88, 605-619.

Castagnetti, S. A., Massaro, S., \& Proto, E. (2018). The Influence of Anger on Strategic Cooperative Interactions. Academy of Management Proceedings (p. 14162). Briarcliff Manor, NY: Academy of Management.

Chartrand, T. L., \& Bargh, J. A. (2002). Nonconscious motivations: Their activation, operation, and consequences. In A. Tesser, D. A. Stapel, \& J. V. Wood (Eds.), Self and Motivation: Emerging Psychological Perspectives (pp. 13-41). Washington, DC, US: American Psychological Association.

Christopoulos, G. I., Uy, M. A., \& Yap, W. J. (2019). The body and the brain: measuring skin conductance responses to understand the emotional experience. Organizational Research Methods, 22, 394-420.

Cooper, J. C., \& Knutson, B. (2008). Valence and salience contribute to nucleus accumbens activation. Neuroimage, 39, 538-547.

Coricelli, G., Dolan, R. J., \& Sirigu, A. (2007). Brain, emotion and decision making: the paradigmatic example of regret. Trends in cognitive sciences, 11, 258-265.

Cropanzano, R. S., Massaro, S., \& Becker, W. J. (2017). Deontic justice and organizational neuroscience. Journal of Business Ethics, 144, 733-754.

Cropanzano, R., Goldman, B., \& Folger, R. (2003). Deontic justice: The role of moral principles in workplace fairness. Journal of Organizational Behavior, 24, 1019-1024.

Cunningham, W. A., Van Bavel, J. J., \& Johnsen, I. R. (2008). Affective flexibility: evaluative processing goals shape amygdala activity. Psychological Science, 19, 152-160. 
Damasio, A. R. (1996). The somatic marker hypothesis and the possible functions of the prefrontal cortex. Philosophical Transactions of the Royal Society B: Biological Sciences, $351,1413-1420$.

Darwin, C. R. (1896). The expression of emotions in man and animals. New York, NY: Philosophical Library.

Davidson, R. J., \& Irwin, W. (1999). The functional neuroanatomy of emotion and affective style. Trends in Cognitive Sciences, 3, 11-21.

Day, M., Boardman, M. C., \& Krueger, N. F. (Eds.). (2017). Handbook of research methodologies and design in neuroentrepreneurship. Cheltenham, UK: Edward Elgar Publishing.

Decety, J. (2010). The neurodevelopment of empathy in humans. Developmental Neuroscience, 32, 257-267.

Denson, T. F., Grisham, J. R., \& Moulds, M. L. (2011). Cognitive reappraisal increases heart rate variability in response to an anger provocation. Motivation and Emotion, 35, 14-22.

Denson, T. F., Pedersen, W. C., Ronquillo, J., \& Nandy, A. S. (2009). The angry brain: neural correlates of anger, angry rumination, and aggressive personality. Journal of Cognitive Neuroscience, 21, 734-744.

Descartes, R., 1989. The passions of the soul. Indianapolis: Hackett Publishing (Voss, S. H. trans.).

Dodell-Feder, D., Koster-Hale, J., Bedny, M., \& Saxe, R. (2011). fMRI item analysis in a theory of mind task. Neuroimage, 55, 705-712.

Drover, W., Massaro, S., Cerf, M., \& Busenitz, L. (2017). Neuro-Entrepreneurship. Academy of Management Proceedings (p. 13893). Briarcliff Manor, NY: Academy of Management. 
Dunsmoor, J. E., Niv, Y., Daw, N., \& Phelps, E. A. (2015). Rethinking extinction. Neuron, 88(1), 47-63.

Dziobek, I., Fleck, S., Kalbe, E., Rogers, K., Hassenstab, J., Brand, M., ... \& Convit, A. (2006). Introducing MASC: a movie for the assessment of social cognition. Journal of Autism and Developmental Disorders, 36, 623-636.

Ekman, P. (1992). An argument for basic emotions. Cognition and Emotion, 6, 169-200.

Ekman, P. (1994). Strong evidence for Universals in facial expressions: a reply to Russell's mistaken critique. Psychological Bulletin, 115, 268-287.

Ekman, P. E., \& Davidson, R. J. (1994). The nature of emotion: Fundamental questions. New York, NY: Oxford University Press.

Ekman, P., Friesen, W.V., \& Ellsworth, P. (1972). Emotion in the Human Face. New York, NY: Pergamon.

Elfenbein, H. A. (2007). Emotion in organizations: a review and theoretical integration. Academy of Management Annals, 1, 315-386.

Ewbank, M. P., Barnard, P. J., Croucher, C. J., Ramponi, C., \& Calder, A. J. (2009). The expressions of fear versus anger. Emotion, 1, 70-83.

Fitness, J. (2000). Anger in the workplace: an emotion script approach to anger episodes between workers and their superiors, co-workers and subordinates. Journal of Organizational Behavior, 21, 147-162.

Friedman, R., Anderson, C., Brett, J., Olekalns, M., Goates, N., \& Lisco, C. C. (2004). The positive and negative effects of anger on dispute resolution: evidence from electronically mediated disputes. Journal of Applied Psychology, 89, 369-376. 
Gallese, V., \& Goldman, A. (1998). Mirror neurons and the simulation theory of mind-reading. Trends in Cognitive Sciences, 2, 493-501.

Geddes, D., \& Callister, R. R. (2007). Crossing the line(s): A dual threshold model of anger in organizations. Academy of Management Review, 32, 721-746.

Gehring, W. J., \& Willoughby, A. R. (2002). The medial frontal cortex and the rapid processing of monetary gains and losses. Science, 295, 2279-2282.

George, M. S., Ketter, T. A., Parekh, P. I., Horwitz, B., Herscovitch, P., \& Post, R. M. (1995). Brain activity during transient sadness and happiness in healthy women. American Journal of Psychiatry, 152, 341-351.

Gibson, D. E., \& Callister, R. R. (2010). Anger in organizations: Review and integration. Journal of Management, 36, 66-93.

Glomb, T. M. (2002). Workplace anger and aggression: informing conceptual models with data from specific encounters. Journal of Occupational Health Psychology, 7, 20-36.

Gooty, J., Gavin, M., \& Ashkanasy, N. M. (2009). Emotions research in OB: The challenges that lie ahead. Journal of Organizational Behavior, 30, 833-838.

Grandey, A. A. (2000). Emotional regulation in the workplace: A new way to conceptualize emotional labor. Journal of Occupational Health Psychology, 5(1), 95-110.

Halgren, E., Walter, R. D., Cherlow, D. G., \& Crandall, P. H. (1978). Mental phenomena evoked by electrical stimulation of the human hippocampal formation and amygdala. Brain: A Journal of Neurology, 101, 83-115.

Hareli, S., \& Rafaeli, A. (2008). Emotion cycles: On the social influence of emotion in organizations. Research in Organizational Behavior, 28, 35-59. 
Hazlett, R. L., \& Hazlett, S. Y. (1999). Emotional response to television commercials: Facial EMG vs. self-report. Journal of Advertising Research, 39, 7-7.

Healey, M. P., Hodgkinson, G. P., \& Massaro, S. (2018). Can Brains Manage? The Brain, Emotion, and Cognition in Organizations. In Individual, Relational, and Contextual Dynamics of Emotions (Research on Emotion in Organizations, Volume 14) (pp. 27-58). Bingley, UK: Emerald Publishing Limited.

Higgins, E. T. (1996). Knowledge Activation: Accessibility, and salience. In E. T. Higgins \& A.W. Kruglanski (Eds.), Social psychology: Handbook of basic principles (pp. 133-168). New York, NY: Guilford Press.

Hippocrates, J. C., \& Mann, W. N. (2000). On The Sacred Disease. DC Stevenson, Web Atomics.

James, W. (1884). What is an emotion?. Mind, 9, 188-205.

Jones, C. L., Ward, J., \& Critchley, H. D. (2010). The neuropsychological impact of insular cortex lesions. Journal of Neurology, Neurosurgery \& Psychiatry, 81, 611-618.

Jones, E. G. (2012). The Thalamus. New York, NY: Plenum Press.

Kanske, P., Böckler, A., Trautwein, F. M., \& Singer, T. (2015). Dissecting the social brain: Introducing the EmpaToM to reveal distinct neural networks and brain-behavior relations for empathy and Theory of Mind. NeuroImage, 122, 6-19.

Kellett, J. B., Humphrey, R. H., \& Sleeth, R. G. (2002). Empathy and complex task performance: Two routes to leadership. The Leadership Quarterly, 13, 523-544.

Keysers, C. (2009). Mirror neurons. Current Biology, 19, 971-973.

Keysers, C., \& Gazzola, V. (2006). Towards a unifying neural theory of social cognition. Progress in Brain Research, 156, 379-401. 
Kiefer, T. (2002). Analyzing emotions for a better understanding of organizational change: Fear, joy, and anger during a merger. In N. Ashkanasy, C. Härtel, \& W. Zerbe (Eds.), Managing emotions in the workplace. Armonk, NY: M. E. Sharpe.

Kreibig, S. D. (2010). Autonomic nervous system activity in emotion: A review. Biological Psychology, 84, 394-421.

Krueger, F., Barbey, A. K., McCabe, K., Strenziok, M., Zamboni, G., Solomon, J., ... \&

Grafman, J. (2009). The neural bases of key competencies of emotional intelligence.

Proceedings of the National Academy of Sciences, 106, 22486-22491.

LaBar, K. S., LeDoux, J. E., Spencer, D. D., \& Phelps, E. A. (1995). Impaired fear conditioning following unilateral temporal lobectomy in humans. Journal of Neuroscience, 15, 68466855.

Lane, R. D., \& Nadel, L. (Eds.). (1999). Cognitive neuroscience of emotion. New York, NY: Oxford University Press.

Lane, R. D., Reiman, E. M., Axelrod, B., Yun, L. S., Holmes, A., \& Schwartz, G. E. (1998). Neural correlates of levels of emotional awareness: Evidence of an interaction between emotion and attention in the anterior cingulate cortex. Journal of Cognitive Neuroscience, $10, \widehat{525-535 .}$

Law, K. S., Wong, C. S., \& Song, L. J. (2004). The construct and criterion validity of emotional intelligence and its potential utility for management studies. Journal of Applied Psychology, 89(3), 483-496.

Lazarus, R. S. (1982). Thoughts on the relations between emotion and cognition. American Psychologist, 37(9), 1019-1024. 
Lazarus, R. S., \& Cohen-Charash, Y. (2001). Discrete emotions in organizational life. In R. Payne and C. L. Cooper (E ds.) Emotions in Organizations (pp. 48-81). Chichester, UK: Wiley.

LeDoux, J. (1998). The emotional brain: The mysterious underpinnings of emotional life. New York, NY: Simon and Schuster.

LeDoux, J. (2003). The emotional brain, fear, and the amygdala. Cellular and Molecular Neurobiology, 23, 727-738.

LeDoux, J. E. (2000). Emotion circuits in the brain. Annual Review of Neuroscience, 23, 155184.

Lee, K., \& Allen, N. J. (2002). Organizational citizenship behavior and workplace deviance: The role of affect and cognitions. Journal of Applied Psychology, 87, 131-142.

Lee, N., Senior, C., \& Butler, M. J. (2012). The domain of organizational cognitive neuroscience: Theoretical and empirical challenges. Journal of Management, 38, 921-931.

Lewis, K. M. (2000). When leaders display emotion: How followers respond to negative emotional expression of male and female leaders. Journal of Organizational Behavior, 21, $221-234$.

Lewis, M. (1993). Self-conscious emotions: Embarrassment, pride, shame, and guilt. In M. Lewis \& J. M. Haviland (Eds.), Handbook of emotions (pp. 563-573). New York, NY: Guilford Press.

Lieberman, M. D. (2007). Social cognitive neuroscience: a review of core processes. Annual Review of Psychology, 58, 259-289.

Lindquist, K. A., Wager, T. D., Kober, H., Bliss-Moreau, E., \& Barrett, L. F. (2012). The brain basis of emotion: a meta-analytic review. Behavioral and Brain Sciences, 35, 121-143. 
Liotti, M., Mayberg, H. S., Brannan, S. K., McGinnis, S., Jerabek, P., \& Fox, P. T. (2000). Differential limbic-cortical correlates of sadness and anxiety in healthy subjects: implications for affective disorders. Biological Psychiatry, 48, 30-42.

Louis, M. R. (1980). Surprise and sense making: What newcomers experience in entering unfamiliar organizational settings. Administrative Science Quarterly, 25, 226-251.

Lövheim, H. (2012). A new three-dimensional model for emotions and monoamine neurotransmitters. Medical Hypotheses, 78, 341-348.

Lyubomirsky, S., King, L., \& Diener, E. (2005). The benefits of frequent positive affect: Does happiness lead to success?. Psychological Bulletin, 131, 803-855.

MacLean, P. D. (1952). Some psychiatric implications of physiological studies on frontotemporal portion of limbic system (visceral brain). Clinical Neurophysiology, 4, $407-418$.

Massaro, S. (2014). Neuroscience: Promising tools to advance organizational research on affect. In Academy of Management Proceedings (p. 12260). Briarcliff Manor, NY: Academy of Management.

Massaro, S. (2015). Neuroscientific Methods Applications in Strategic Management. In Dagnino G. \& Cinci C. (Eds.), Strategic Management: A Research Method Handbook (pp. 253282). New York, NY: Routledge.

Massaro, S. (2017). Neuroscience Methods: A Framework for Managerial and Organizational Cognition. In R. J. Galavan, K. J. Sund, \& G. P. Hodgkinson (Eds.), Methodological Challenges and Advances in Managerial and Organizational Cognition (pp. 241-278). Bingley, UK: Emerald Publishing Limited. 
Massaro, S., \& Becker, W. J. (2015). Organizational justice through the window of neuroscience. In D. Waldman \& P. Baltazhard (Eds.) Organizational Neuroscience (pp. 257-276). Bingley, UK: Emerald Group Publishing Limited.

Massaro, S., \& Pecchia, L. (2019). Heart rate variability (HRV) analysis: A methodology for organizational neuroscience. Organizational Research Methods, 22, 354-393.

Mataix-Cols, D., An, S. K., Lawrence, N. S., Caseras, X., Speckens, A., Giampietro, V., ... \& Phillips, M. L. (2008). Individual differences in disgust sensitivity modulate neural responses to aversive/disgusting stimuli. European Journal of Neuroscience, 27, 30503058.

Moll, J., de Oliveira-Souza, R., Moll, F. T., Ignácio, F. A., Bramati, I. E., Caparelli-Dáquer, E. M., \& Eslinger, P. J. (2005). The moral affiliations of disgust: A functional MRI study. Cognitive and Behavioral Neurology, 18, 68-78.

Müller-Pinzler, L., Krach, S., Krämer, U. M., \& Paulus, F. M. (2016). The social neuroscience of interpersonal emotions. In Social behavior from rodents to humans (pp. 241-256). Springer.

Murphy, F. C., Nimmo-Smith, I. A. N., \& Lawrence, A. D. (2003). Functional neuroanatomy of emotions: a meta-analysis. Cognitive, Affective, \& Behavioral Neuroscience, 3, 207-233.

Ochsner, K. N., \& Gross, J. J. (2005). The cognitive control of emotion. Trends in Cognitive Sciences, 9, 242-249.

Ochsner, K. N., \& Lieberman, M. D. (2001). The emergence of social cognitive neuroscience. American Psychologist, 56, 717-734. 
Ochsner, K. N., Bunge, S. A., Gross, J. J., \& Gabrieli, J. D. (2002). Rethinking feelings: an fMRI study of the cognitive regulation of emotion. Journal of Cognitive Neuroscience, 14, 12151229.

Ortony, A., \& Turner, T. J. (1990). What's basic about basic emotions?. Psychological Review, 97(3), 315-331.

Panksepp, J. (1998). Affective neuroscience: The foundations of human and animal emotions. New York, NY: Oxford University Press.

Papez, J. W. (1937). A proposed mechanism of emotion. Archives of Neurology \& Psychiatry, 38, 725-743.

Pelzer, P. (2002). Disgust and organization. Human Relations, 55, 841-860.

Phan, K. L., Wager, T., Taylor, S. F., \& Liberzon, I. (2002). Functional neuroanatomy of emotion: a meta-analysis of emotion activation studies in PET and fMRI. Neuroimage, 16, $331-348$.

Phelps, E. A. (2009). The study of emotion in neuroeconomics. In P. W. Glimcher, C. F. Camerer, E. Fehr, and R. A. Poldrack (Eds.). Neuroeconomics: Decision making and the brain (pp. 233-250). London, UK: Academic Press.

Phelps, E. A., Delgado, M. R., Nearing, K. I., \& LeDoux, J. E. (2004). Extinction learning in humans: role of the amygdala and vmPFC. Neuron, 43, 897-905.

Plutchik, R. (1980). Emotion: A Psychoevolutionary Synthesis. New York, NY: Harper \& Row.

Porath, C. L., \& Pearson, C. M. (2012). Emotional and behavioral responses to workplace incivility and the impact of hierarchical status. Journal of Applied Social Psychology, 42, $326-357$.

Powell, T. C. (2011). Neurostrategy. Strategic Management Journal, 32, 1484-1499. 
Rafaeli, A., \& Sutton, R. I. (1989). The expression of emotion in organizational life. Research in Organizational Behavior, 11, 1-42.

Rainville, P., Bechara, A., Naqvi, N., \& Damasio, A. R. (2006). Basic emotions are associated with distinct patterns of cardiorespiratory activity. International Journal of Psychophysiology, 61, 5-18.

Rauch, S. L., Shin, L. M., Dougherty, D. D., Alpert, N. M., Orr, S. P., Lasko, M., .. \& Pitman, R. K. (1999). Neural activation during sexual and competitive arousal in healthy men. Psychiatry Research: Neuroimaging, 91, 1-10.

Rizzolatti, G., \& Craighero, L. (2004). The mirror-neuron system. Annual Review Neuroscience, 27, 169-192.

Rolls, E. T. (2000). On the brain and emotion. Behavioral and Brain Sciences, 23, 219-228.

Rozin, P., \& Fallon, A. E. (1987). A perspective on disgust. Psychological Review, 94, 23-41.

Ruby, P., \& Decety, J. (2004). How would you feel versus how do you think she would feel? A neuroimaging study of perspective-taking with social emotions. Journal of Cognitive Neuroscience, 16, 988-999.

Rushworth, M. F., \& Behrens, T. E. (2008). Choice, uncertainty and value in prefrontal and cingulate cortex. Nature Neuroscience, 11, 389-397.

Ryan, R. M., \& Deci, E. L. (2001). On happiness and human potentials: A review of research on hedonic and eudaimonic well-being. Annual Review of Psychology, 52, 141-166.

Sato, W., Fujimura, T., \& Suzuki, N. (2008). Enhanced facial EMG activity in response to dynamic facial expressions. International Journal of Psychophysiology, 70, 70-74. 
Sato, W., Kochiyama, T., Uono, S., Kubota, Y., Sawada, R., Yoshimura, S., \& Toichi, M. (2015). The structural neural substrate of subjective happiness. Scientific Reports, 5(16891).

Schurz, M., Radua, J., Aichhorn, M., Richlan, F., \& Perner, J. (2014). Fractionating theory of mind: a meta-analysis of functional brain imaging studies. Neuroscience \& Biobehavioral Reviews, 42, 9-34.

Singer, T. (2009). Understanding others: brain mechanisms of theory of mind and empathy. In P. W. Glimcher, C. F. Camerer, E. Fehr, and R. A. Poldrack (Eds.). Neuroeconomics: Decision making and the brain (pp. 249-266). London, UK: Academic Press.

Singer, T., Seymour, B., O’Doherty, J., Kaube, H., Dolan, R. J., \& Frith, C. D. (2004). Empathy for pain involves the affective but not sensory components of pain. Science, 303, 11571162.

Skarlicki, D. P., Hoegg, J., Aquino, K., \& Nadisic, T. (2013). Does injustice affect your sense of taste and smell? The mediating role of moral disgust. Journal of Experimental Social Psychology, 49, 852-859.

Sprengelmeyer, R., Rausch, M., Eysel, U. T., \& Przuntek, H. (1998). Neural structures associated with recognition of facial expressions of basic emotions. Proceedings of the Royal Society of London B: Biological Sciences, 265, 1927-1931.

Stemmler, G., Heldmann, M., Pauls, C. A., \& Scherer, T. (2001). Constraints for emotion specificity in fear and anger: The context counts. Psychophysiology, 38, 275-291.

Tangney, J. P., Stuewig, J., \& Mashek, D. J. (2007). What's moral about the self-conscious emotions? In J. L. Tracy, R. W. Robins, \& J. P. Tangney (Eds.), The self-conscious emotions: Theory and research (pp. 21-37). New York, NY: The Guilford Press. 
Tau, G. Z., \& Peterson, B. S. (2010). Normal development of brain circuits. Neuropsychopharmacology, 35, 147-168.

Telzer, E. H. (2016). Dopaminergic reward sensitivity can promote adolescent health: A new perspective on the mechanism of ventral striatum activation. Developmental Cognitive Neuroscience, 17, 57-67.

Teplan, M. (2002). Fundamentals of EEG measurement. Measurement Science Review, 2, 1-11.

Thatcher, R. W., North, D., \& Biver, C. (2007). Intelligence and EEG current density using lowresolution electromagnetic tomography (LORETA). Human Brain Mapping, 28, 118-133.

Thoresen, C. J., Kaplan, S. A., Barsky, A. P., Warren, C. R., \& de Chermont, K. (2003). The Affective Underpinnings of Job Perceptions and Attitudes: A Meta-Analytic Review and Integration. Psychological Bulletin, 129, 914-945.

Thorson, K. R., West, T. V., \& Mendes, W. B. (2018). Measuring physiological influence in dyads: A guide to designing, implementing, and analyzing dyadic physiological studies. Psychological Methods, 23(4), 595-616.

Van den Bos, K., Maas, M., Waldring, I. E., \& Semin, G. R. (2003). Toward understanding the psychology of reactions to perceived fairness: The role of affect intensity. Social Justice Research, 16, 151-168.

Van Dillen, L. F., Heslenfeld, D. J., \& Koole, S. L. (2009). Tuning down the emotional brain: an fMRI study of the effects of cognitive load on the processing of affective images. Neuroimage, 45, 1212-1219.

Wager, T. D., \& Atlas, L. Y. (2015). The neuroscience of placebo effects: connecting context, learning and health. Nature Reviews Neuroscience, 16, 403-418. 
Waldman, D. A., Balthazard, P. A., \& Peterson, S. J. (2011). Leadership and neuroscience: Can we revolutionize the way that inspirational leaders are identified and developed?. Academy of Management Perspectives, 25, 60-74.

Walter, H., Adenzato, M., Ciaramidaro, A., Enrici, I., Pia, L., \& Bara, B. G. (2004). Understanding intentions in social interaction: the role of the anterior paracingulate cortex. Journal of Cognitive Neuroscience, 16, 1854-1863.

Ward, J. (2015). The student's guide to cognitive neuroscience. New York, NY: Psychology Press.

Weiss, H. M., \& Beal, D. (2005). Weiss, H. M. \& Beal, D. J. (2005). Reflections on Affective Events Theory. In N. M. Ashkanasy, W. J. Zerbe, \& C. E. Härtel (Eds.), Research on emotions in organizations, Vol. 1: The effect of affect in organizational settings (pp. 1- 21). San Diego, CA: Elsevier.

Weiss, H. M., \& Cropanzano, R. (1996). Affective events theory: A theoretical discussion of the structure, causes and consequences of affective experiences at work. Research in Organizational Behavior, 18, 1-74.

Wessel, J. R., Danielmeier, C., Morton, J. B., \& Ullsperger, M. (2012). Surprise and error: common neuronal architecture for the processing of errors and novelty. Journal of Neuroscience, 32, 7528-7537.

Whalen, P. J., Rauch, S. L., Etcoff, N. L., McInerney, S. C., Lee, M. B., \& Jenike, M. A. (1998). Masked presentations of emotional facial expressions modulate amygdala activity without explicit knowledge. Journal of Neuroscience, 18, 411-418. 
Whalen, P. J., Shin, L. M., McInerney, S. C., Fischer, H., Wright, C. I., \& Rauch, S. L. (2001). A functional MRI study of human amygdala responses to facial expressions of fear versus anger. Emotion, 1, 70-83.

Wicker, B., Keysers, C., Plailly, J., Royet, J. P., Gallese, V., \& Rizzolatti, G. (2003). Both of us disgusted in My insula: the common neural basis of seeing and feeling disgust. Neuron, 40, $655-664$.

Wiersma, U. J. (1992). The effects of extrinsic rewards in intrinsic motivation: A meta-analysis. Journal of Occupational and Organizational Psychology, 65, 101-114.

Wolf, I., Dziobek, I., \& Heekeren, H. R. (2010). Neural correlates of social cognition in naturalistic settings: a model-free analysis approach. Neuroimage, 49, 894-904.

Yarkoni, T., Poldrack, R. A., Nichols, T. E., Van Essen, D. C., \& Wager, T. D. (2011). Largescale automated synthesis of human functional neuroimaging data. Nature Methods, 8 , $665-670$.

Zajonc, R. B. (1984). On the primacy of affect. American Psychologist, 39, 117-123. 


\section{Figures and Tables}

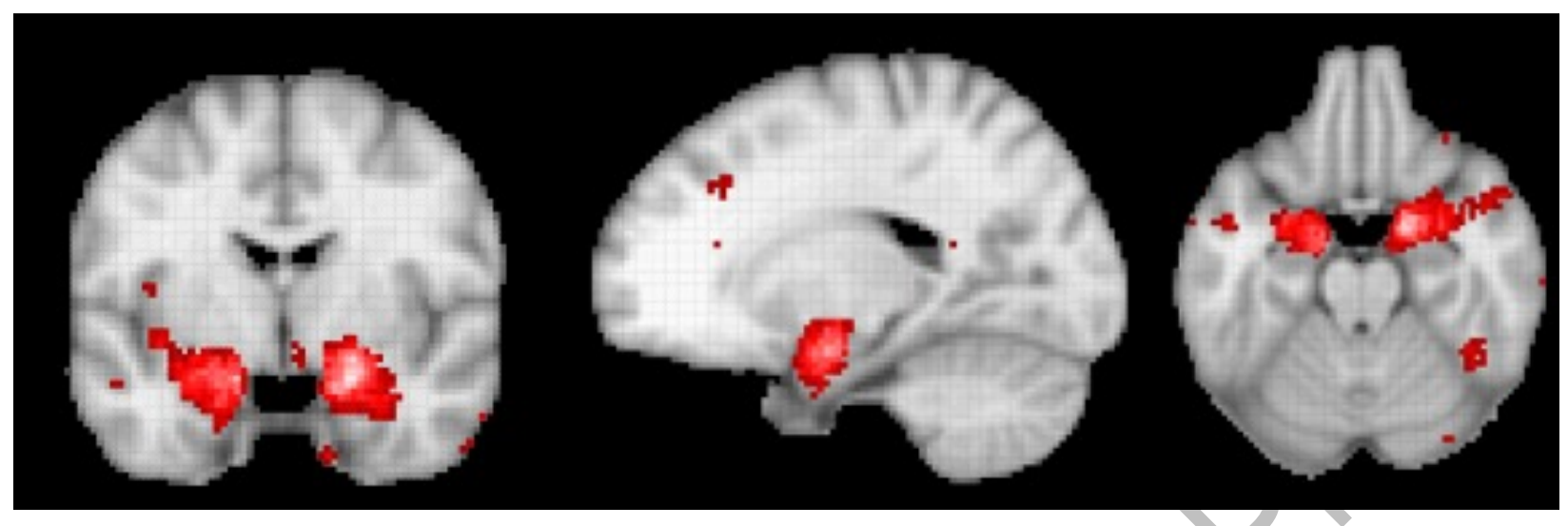

Figure 3.1. Activations peaks (in red) of brain structures conventionally associated with the limbic circuit. Images were obtained by performing a meta-analysis of over $400 \mathrm{fMRI}$ activation studies, published between 1992 and 2018, which reported "emotion(s)" as a keyword (Yarkoni, Poldrack, Nichols, Van Essen, \& Wager, 2011). 


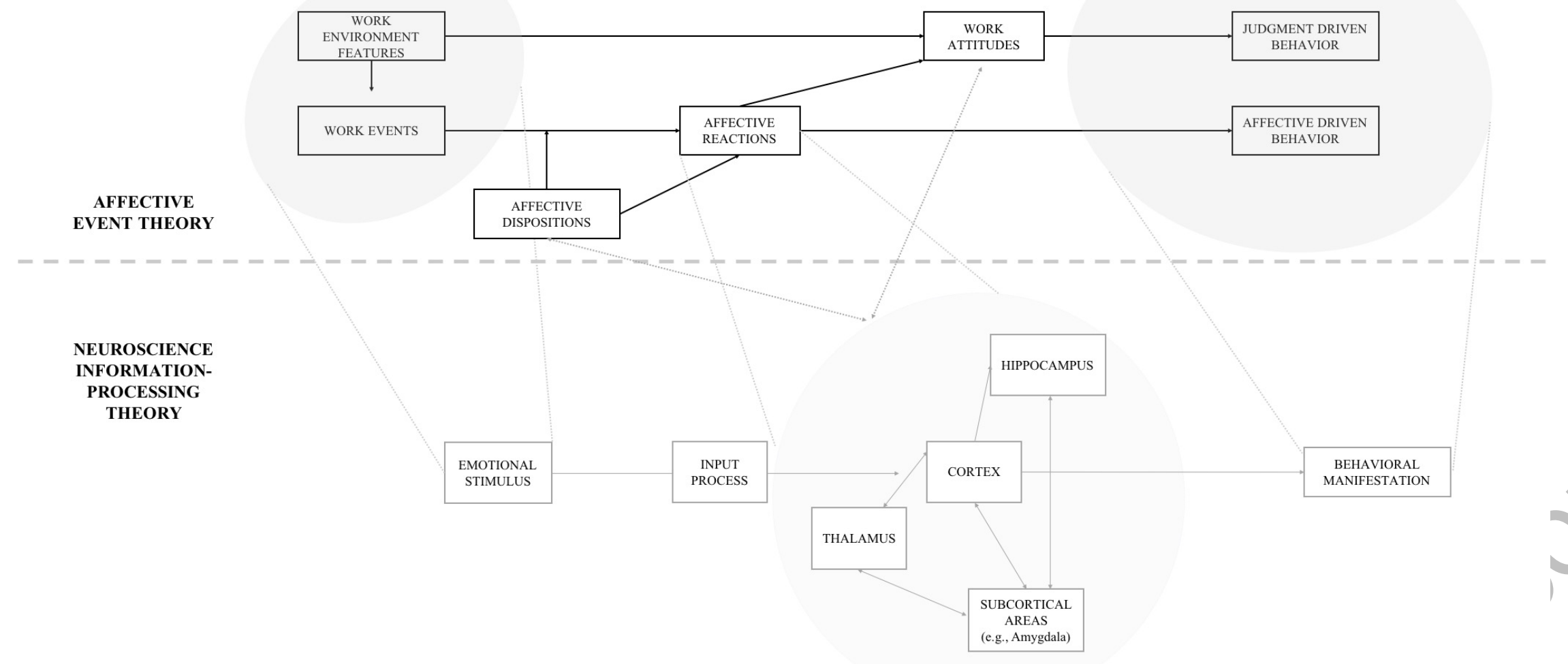

Figure 3.2. Integration of Affective Event Theory (Weiss \& Cropanzano, 1996) with an Organizational Neuroscience perspective to disentangle the core brain structures and mechanisms involved in "affective reactions." 
Table 3.1.

Classification of Organizational Neuroscience Methods Based on Their Testing Rationale (adapted from Massaro, 2017).

\begin{tabular}{|c|c|c|}
\hline Type of test & Definition & $\begin{array}{l}\text { Method linking regional neural activity } \\
\text { to mental function }\end{array}$ \\
\hline Association & $\begin{array}{l}\text { Those experimental methods that implicate a manipulation of a } \\
\text { psychological state or behavior, the simultaneous measurements } \\
\text { of the neural activity, and the following analysis of the }\end{array}$ & $\begin{array}{l}\text { fMRI } \\
\text { PET } \\
\text { EEG }\end{array}$ \\
\hline & correlation between the two. & $\begin{array}{l}\text { MEG } \\
\text { Physiological (HRV; Skin Conductance) }\end{array}$ \\
\hline Necessity & $\begin{array}{l}\text { Those that involve a disruption of the neural activity and aim to } \\
\text { show how this event impairs a specific behavior or } \\
\text { psychological function. }\end{array}$ & $\begin{array}{l}\text { Lesion studies } \\
\text { TMS }\end{array}$ \\
\hline Sufficiency & $\begin{array}{l}\text { Those enhancing a neural activity and seeking to establish that } \\
\text { this process results in a specific behavior or psychological state. }\end{array}$ & TMS (anodal) \\
\hline
\end{tabular}

